\title{
A New Technique for Recovering Bacteria Stored in Liquid Nitrogen
}

\author{
By J. J. BULLEN \\ National Institute for Medical Research, Mill Hill, London $N_{7}$ I AA \\ (Received 5 February 1975; revised 26 February 1975) \\ INTRODUCTION
}

The storage of bacterial cultures in liquid nitrogen has many advantages. The low temperature $\left(-196^{\circ} \mathrm{C}\right)$ ensures that all metabolic activity is suspended (Wilson \& Miles, 1966; Swoager, 1973). In addition, cultures that survive freezing and thawing probably remain viable indefinitely, and genetic changes are unlikely to occur (Swoager, 1973). Present techniques, however, have one great disadvantage: the relatively large amount of space required for individual vials means that the method is unsatisfactory if repeated samples of the same culture are required. For example, a 351 container will hold approximately $675 \mathrm{I}-\mathrm{ml}$ vials. If 50 successive samples of each culture are required for experimental work the holding capacity is reduced to 13 cultures. On the other hand if one $5-\mathrm{ml}$ vial could be made to provide an almost unlimited number of subcultures a 351 container could store 405 cultures for continuous use.

It is not possible to obtain repeated subcultures from a single vial by repeated thawing and refreezing since this leads to rapid death of the bacteria (Mazur, 1966). This difficulty can be circumvented if a minute sample of the culture can be removed while it is still frozen. It is not practicable to scrape the frozen surface with a wire or blade as this often leads to fragmentation of the surface and the expulsion of particles of culture from the tube. This is highly undesirable in any circumstance and dangerous in the case of pathogenic organisms. The technique described here enables repeated samples to be taken from frozen cultures, with safety and without risk of contamination.

\section{METHODS}

Cultures for freezing were grown for $18 \mathrm{~h}$ in nutrient broth to give viable counts of $10^{8}$ to $10^{9} / \mathrm{ml}$. Portions $(4 \mathrm{ml})$ were frozen rapidly by immersing the tubes directly in the liquid nitrogen within the storage container.

The sampling device shown in Fig. $I$ is a stainless-steel tool constructed to fit into a $5 \mathrm{ml}$ plastic tube (holding $4.0 \mathrm{ml}$ of culture) which is normally sealed with a screw cap and silicone rubber washer (Sterilin Ampoule No. 507; Sterilin, Richmond, Surrey). The base of the tool $(9.6 \mathrm{~mm}$ diameter) has numerous small pyramidal teeth (Fig. I $b)$. The shaft $(8.5 \mathrm{~cm}$ long) runs through a plastic stopper ( $2 \mathrm{~cm}$ long) made of Delrin (Du Pont de Nemours, Delaware, U.S.A.). This is grooved to screw into the internal thread of the plastic tube, and provides a complete seal during the sampling operation. The tool is sterilized by autoclaving.

The culture tube is removed from the liquid nitrogen and clamped at an angle of $45^{\circ}$ in a retort stand in a walk-in sterile cabinet. The cap is removed and placed upright in a sterile Petri dish and covered with the Petri dish lid. The sterile sampling tool is threaded into the tube. The operator wears sterile rubber gloves and does not touch the surface of the shaft until the sample has been taken. Two rapid turns of the handle with one hand are sufficient to take a sample, the tool being gripped by the plastic stopper with the other hand. The 

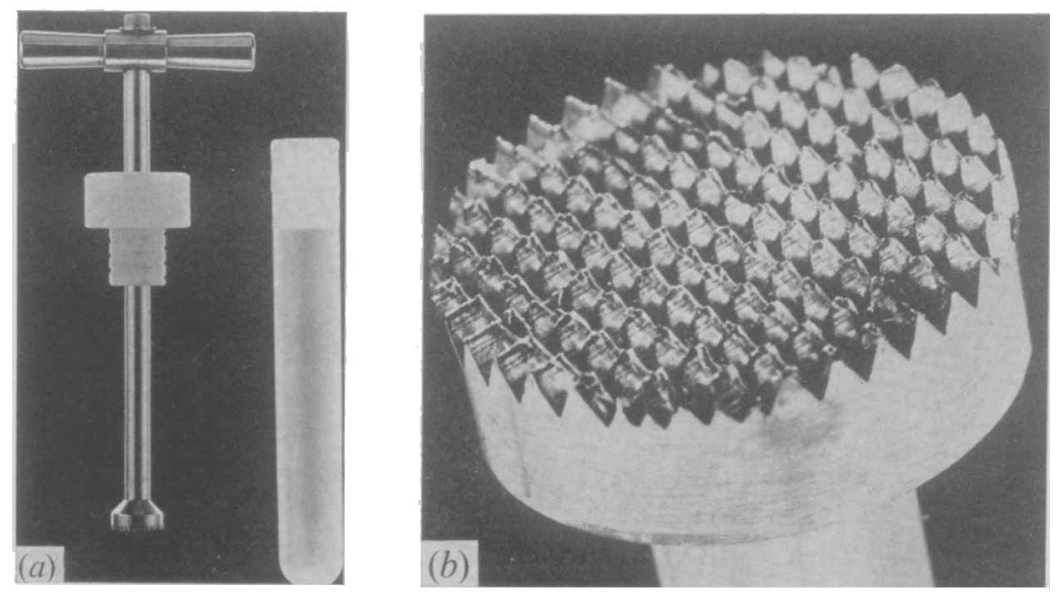

Fig. I. (a) Stainless-steel sampling tool with grooved plastic stopper for insertion into Sterilin $5 \mathrm{ml}$ ampoule. (b) Pyramidal teeth at the end of the sampling tool.

stopper is then unscrewed and the end of the tool dabbed on to the surface of an agar plate and then into $20 \mathrm{ml}$ of broth. The tube cap is replaced and the culture returned to the liquid nitrogen. The amount of culture removed is usually too small to be seen with the naked eye and the metal teeth usually appear quite dry, but since the culture initially contains $10^{8}$ to $10^{9}$ viable bacteria/ml a heavy growth invariably develops on the agar plate and in the broth. The diameter of the base of the sampling tool is only slightly less than the internal diameter of the culture tube so that the sample is removed from the entire surface of the culture. This prevents any fragmentation of the frozen surface.

Sampling takes approximately $3.5 \mathrm{~min}$ from the time the culture is removed from the liquid nitrogen to the time it is put back. The temperature of the frozen culture after removal from the container was measured by a $\mathrm{Ni} \mathrm{Cr} / \mathrm{Ni} \mathrm{Al}$ thermocouple embedded $2 \mathrm{~cm}$ below the surface and connected to a Comarck type $\mathrm{I} 66 \mathrm{C}$ electronic thermometer. The temperature rose rapidly to $-90^{\circ} \mathrm{C}$ in $2 \mathrm{~min}$ but even after $4 \mathrm{~min}$ was between -40 and $-50{ }^{\circ} \mathrm{C}$. Thus there is no danger of the culture thawing during the sampling operation.

\section{RESULTS AND DISCUSSION}

During the past few months a virulent Pseudomonas aeruginosa culture stored in liquid nitrogen has been repeatedly sampled without apparent loss of viability, or contamination. It was important to screw up the cap of the plastic tube gently, since over-tightening distorted the silicone washer and this allowed entry of liquid nitrogen. This difficulty can largely be overcome if the washer and thread of the cap are coated with Silicone High Vacuum Grease (Edwards High Vacuum Ltd) and the cap sterilized by autoclaving. The virulence of this $P$. aeruginosa for mice can decrease fairly rapidly when it is stored at $+4{ }^{\circ} \mathrm{C}$ or at $-20^{\circ} \mathrm{C}$. The same strain kept in liquid nitrogen for $\mathrm{I} 2$ months showed no loss of virulence.

The technique described is simple and safe to operate and a great convenience in providing a constant source of bacteria with stable characteristics. There is also a great saving in storage space, and considerable saving in the time and effort normally required to preserve cultures.

Thanks are due to Mr W. J. B. Tegg, N.I.M.R., for construction of the sampling tool, and to Mr S. N. Wallis, N.I.M.R., for valuable technical help. 


\section{REFERE NCES}

Mazur, P. (1966). Basis of freezing injury. In Cryobiology, pp. 213-315. Edited by H. T. Merryman. London and New York: Academic Press.

SwOAGER, W. C. (1973). By liquid nitrogen refrigeration. International Laboratory (Jan./Feb.), 42-46.

Wirson, G. S. \& MiLes, A. A. (1966). The resistance of bacteria to physical and chemical agents. In Principles of Bacteriology and Immunity, 5th edn, vol. I, pp. 127-172. London: Arnold. 